\title{
THE ROLE OF SOCIAL AXIOMS IN PREDICTING LIFE SATISFACTION: A LONGITUDINAL STUDY IN HONG KONG*
}

\begin{abstract}
Data from a 1-year, longitudinal study were utilized to explore the role of five pan-cultural beliefs about the world (social axioms) in predicting life satisfaction. It was hypothesized that higher levels of social cynicism would predict lower satisfaction with life because cynical persons set in motion a self-fulfilling prophecy of unrewarding social outcomes. The negative social feedback thus engendered results in lower levels of self-esteem, which mediates the effect of socially cynical beliefs on life satisfaction. These findings were confirmed in a longitudinal study of Chinese undergraduates in Hong Kong. Their implications were explored by considering the role of beliefs about the world upon additional mediators of life satisfaction in different cultural settings and for engaging in therapeutic interventions with distressed clients.
\end{abstract}

KEY WORDS: Hong Kong Chinese, life satisfaction, social axioms, selfesteem.

Cognitive therapy (Todd and Arthur, 1994) calls our attention to the role of cognitions in promoting one's well-being. Our interest in well-being follows its recognized importance as "the ultimate motivator", "the universal goal" for human beings (Diener, 1984; Diener and Larsen, 1993; Kwan et al., 1997). Given that the cognitive approach emphasizes modification of distorted thinking and unrealistic goals in psychological disorders, can we also identify those cognitions that are related to well-being?

Life satisfaction, the global evaluation of satisfaction with life, has been identified as the cognitive component in assessing

\footnotetext{
" The authors extend their grateful thanks to all members of the Goals Research Team for their hard work during this year-long project.
} 
subjective well-being (see Diener et al., 2003 for review). Past studies on life satisfaction discovered many important cognitive predictors, like optimism, values, self-esteem (Diener et al., 1999), but these predictors are all self-rated personality traits; none has investigated how our cognitions about the external world in which we function relates to life satisfaction.

\section{SOCIAL BELIEFS AND LIFE SATISFACTION}

The newly developed social axioms survey provides a tool for assessing one's belief about how the world functions. According to Leung et al. (2002), "Social axioms are generalized beliefs about oneself (i.e., personhood), the social and physical environment, or the spiritual world, and are in the form of an assertion about the relationship between two entities or concepts" (brackets added, p. 289). These general beliefs are developed through long-term socialization processes, especially as occuring within one's family of origin. The axiom survey consists of five pan-culturally similar dimensions, viz., social cynicism, social complexity, reward for application, fate control, and religiosity. According to Bond et al. (2004b), Social Cynicism "... refers to a negative view of human nature, a view that life produces unhappiness, that people exploit others, and a mistrust of social institutions. Social Complexity refers to the belief in multiple ways of achieving a given outcome, and agreement that human behavior is variable across situations. Reward for Application refers to a general belief that effort, knowledge, and careful planning will lead to positive results. Religiosity refers to a belief in the reality of a supreme being and the positive (social) functions of religious practice. Finally, Fate Control refers to a belief that life events are predetermined and that there are ways for people to influence these fated outcomes." (p. 553). Each of the dimensions is worthwhile of investigation as they address survival and functional concerns guiding social behaviors (Leung and Bond, 2004).

Social beliefs are generalized expectancies for outcomes in the social world, guiding our social behaviors in light of these 
expected consequences. This construct is therefore closely related to the research tradition on cognitive dispositions in well-being, which emphasizes the expectancy about outcomes as crucial in explaining the operation of the optimism trait (Scheier and Carver, 1985), the expectancy of control (Lachman and Weaver, 1998), and positive illusions (Taylor and Armor, 1996), which all promote well-being. Following this logic, we expect that social axioms, i.e., individual explanations of how the social world functions, will reflect each individual's expectancies developed from past experiences with the social world. As expectancies, these beliefs will also guide behaviors whose consequences will in turn affect the individual's self-system.

\section{SOCIAL BELIEFS, SOCIAL EXPERIENCE AND SELF ESTEEM}

Since the identification of the social self and the interdependent self (Kitayama and Markus, 1995), the self is increasingly viewed more as being influenced not only by our personal success but also by our social experiences. We evaluate our sense of worth through social comparisons (Marsh et al., 2000; Shepperd and Taylor, 1999), as well as through the judgments of others (Steele, 1997). Leary (1998) went further to claim that self-esteem varies depending on these social comparisons and that our sense of self-esteem is a social psychological gauge that we monitor and calibrate in response to others' appraisals of our various social performances.

Our social beliefs can affect our social experience. Many studies have found a self-fulfilling effect of beliefs (e.g., Jussim, 1986). We generally perceive, act and interact according to our social expectations, thereby in part generating our own social realities through the social beliefs that we hold. With this hypothesized influence model in mind, we will conduct a study to explore the influence of social beliefs on life satisfaction, with self-esteem as possible mediating variable in the model. We tried to determine a possible causal role of the beliefs in the model by making the study longitudinal in nature. 
We expect that social cynicism will be related to lower selfesteem, and thus to lower life satisfaction. Socially cynical persons hold a negative, suspicious view of human beings, which we propose will lead to negative interactions with others. Consistent with this reasoning, those high in social cynicism have been shown to prefer competition as a method of conflict resolution (Bond et al., 2004a). General use of this interpersonal strategy will eventually lead to unsatisfying social outcomes. Further, as Darley and Fazio (1980) have shown, people who hold negative views towards others will avoid and decrease interactions with them. Therefore, those who are socially cynical tend to have fewer associates and to elicit less social support from those they have. This less sustaining social engagement will be a source of lowered self-esteem, which will lead to lowered life satisfaction.

For the other dimensions of social axioms, we are less certain in our speculations. However, Bond et al.'s (2004a) study of social axioms and styles of conflict resolution provide some possible suggestions about their relationship to self-esteem and life-satisfaction. As reward for application and religiosity relate to the accommodation style of conflict resolution (Bond et al., 2004a), we speculate that those high in these two beliefs will be better liked in the Chinese society, leading such people to have higher self-esteem and thus higher satisfaction with life. A similar logic follows for social complexity, as it is related to the collaborative style of conflict resolution. We cannot provide any speculation about fate control and its link to self-esteem, as it has shown no relation to any style of interpersonal conflict resolution in previous work. So, we cannot predict what social feedback and experience a belief system high in fate control will potentiate to affect self-esteem and life satisfaction. We will explore its possible linkage, however, using the results from the following study.

\section{METHOD}

The present study reports data from a larger longitudinal project on personal goals and the goal pursuit process (Hui, 2004). 


\section{Phase 1}

\section{Participants}

One hundred and thirteen Hong Kong Chinese students were recruited from the Chinese University of Hong Kong (47 males and 65 females); with 98 participants 20 years old or below, and 15 aged from 21 to 30 . Seventy-nine students were recruited in an introductory psychology class as fulfillment of their course requirement. The remaining 34 students were recruited on campus for a $\mathrm{HK} \$ 50$ honorarium.

\section{Procedure}

Participants completed the measures in paper-pencil format during a 1-h experimental session in a group setting. Data were collected in November, 2002.

\section{Measures: social beliefs}

The Social Axioms Survey ( $S A S$ ). The Chinese version of SAS was used, consisting of 60 items derived from a pan-cultural study on social beliefs in five different nations (Leung et al., 2002), with 12 items tapping each of the five social beliefs, namely reward for application, social cynicism, social complexity, fate control, and religiosity. The scale measures the general, context-free beliefs of people developed from human socialization experience (Leung and Bond, 2004). Sample items for the dimensions are: "Kind-hearted people usually suffer losses" for social cynicism; "Adversity can be overcome by effort" for reward for application; "Current losses are not necessarily bad for one's long-term future" for social complexity; "All things in the universe have been determined" for fate control; "Belief in a religion makes people good citizens" for religiosity. Each item was rated on a five-point scale $(1=$ strongly disbelieve to 5 = strongly believe).

\section{Phase 2}

\section{Participants}

Eighty participants from the first study responded to the call for a follow-up study in February, 2003. An honorarium with a maximum of HK\$250 (the amount depending on the number of 
completed online questionnaires) was given in exchange for their participation.

\section{Procedure}

As before, participants completed the measures in paper-pencil format during a 1-h experimental session in a group setting.

\section{Measures}

Satisfaction With Life Scale (SWLS). The five items from the Satisfaction With Life Scale (SWLS) developed by Diener et al. (1985) was used. These five items were used and validated in previous studies with Chinese sample (e.g., Kwan et al., 1997). The SWLS used a seven-point scale $(1=$ strongly disagree to 7 = strongly agree). It was translated into Chinese and administered during the experimental session. In addition, one item from the Delighted-Terrible Scale (D-T Scale) developed by Andrews and Withey (1976) was used. The question asked was, "In general, how do you evaluate about your life until this moment?" The answer was given on a 7-point scale, ranging from 1 - "terrible" to 7 - "delighted".

Self-esteem. The 10-item Rosenberg Self-esteem Scale (RSES: 1965) was used to measure each individual's global self-esteem, which is the extent to which individuals generally assess themselves in a positive way. Respondents rated their sense of personal self-esteem on a four-point scale $(1=$ strongly agree to $4=$ strongly disagree) for each of the 10 items.

\section{Phase 3}

\section{Participants}

The same 80 participants who participated in the phase two study responded to the call for a follow-up experimental session in June, 2003. An honorarium of $\mathrm{HK} \$ 50$ was given for their participation.

\section{Procedures}

The participants were given a 1-h experimental session to fill out in paper and pencil a set of psychological measures, including the SWLS and the Rosenberg Self-esteem Scale. 


\section{Phase 4}

\section{Participants}

Seventy-eight participants from the phase three study responded to the call for a follow-up experimental session in November, 2003. An honorarium of HK $\$ 70$ was given for their participation.

\section{Procedures}

The participants were given a 1-h experimental session to complete a battery of psychological measures, including the SWLS and the Rosenberg Self-esteem Scale.

\section{Summary}

Life satisfaction and self-esteem were collected three times from phase two to four. These longitudinal data will enable a sequenced and more reliable assessment of the psychological constructs, evening out the effects of any temporary environmental stressors on predicting life satisfaction, like the life-threatening Severe Acute Respiratory Syndrome (SARS) epidemic that occurred during the study.

\section{RESULTS}

\section{Preliminary Analyses}

Social axioms

The five social belief dimensions showed high reliabilities with Cronbach alpha levels ranging from 0.87 to 0.96 .

\section{Life satisfaction}

The life satisfaction scores were calculated at each of the three time points. The scale achieved a satisfactory reliability at each time point, with alphas ranging from 0.65 to 0.88 . The average test-retest reliability for this measure was 0.85 , suggesting that life satisfaction is a very stable attribute of an individual. A grand mean score was obtained by averaging the three scores.

\section{Self-esteem}

The item, "I wish I would value myself more", was discarded because the item-whole correlation was always low (ranging 
from 0.16 to 0.31 ), probably because of its ambiguous meaning in the Chinese version. Thereafter, the scale's reliabilities at each of the three time points ranged from 0.88 to 0.91 . The average test-retest reliability for this measure was 0.93 , suggesting that self-esteem was a stable personal attribute. A mean score was obtained across these three time points.

\section{Correlates of life satisfaction}

Consistent with results from past studies, mean self-esteem was positively correlated with mean life satisfaction, showing the strongest correlation among all variables, $r(78)=0.59$, $p<0.01)$. Mean life satisfaction was correlated with social cynicism, $r(78)=-0.39, p<0.01$, as predicted, but also negatively with social complexity, $r(78)=-0.23, p<0.05$. Refer to Table I for a more detailed presentation of these results.

\section{Correlations with self-esteem}

As predicted, social cynicism was negatively correlated with mean self-esteem, $r(78)=-0.39, p<0.01$. Table II.

Social axioms as predictors. To test the predictive power of social axioms as a whole, the five social axioms dimensions were entered into a simple regression analysis. The dimensions together were able to predict life satisfaction, $R^{2}=0.26$, $p<0.01$. The standardized $B$ for social cynicism was -0.99 , $p<0.01$; for other dimensions, the $B$ was insignificant.

Mediating role of self-esteem. Based on the correlation results, we have reason to speculate that the link between social cynical beliefs and mean life satisfaction may be mediated by mean selfesteem. We tested the mediation model according to the procedure proposed by Baron and Kenny (1989). They suggested three steps to test a mediation model involving independent, mediating and outcome variables. The first step is to show that the independent variable predicts the outcome variable. The second step is to show the independent variable predicts the mediator. We know the first step is valid for the social belief 
TABLE I

Correlations between life satisfaction, self-esteem and social beliefs across time points

\begin{tabular}{|c|c|c|c|c|}
\hline & $\begin{array}{l}\text { Life satisfaction } \\
\text { (Time 1) }\end{array}$ & $\begin{array}{l}\text { Life satisfaction } \\
\text { (Time } 2 \text { ) }\end{array}$ & $\begin{array}{l}\text { Life satisfaction } \\
\text { (Time 3) }\end{array}$ & $\begin{array}{l}\text { Mean life } \\
\text { satisfaction }\end{array}$ \\
\hline $\begin{array}{l}\text { Life satisfaction } \\
\quad \text { (Time 1) }\end{array}$ & 1 & $0.71 * *$ & $0.65 * *$ & $0.90 * *$ \\
\hline $\begin{array}{l}\text { Life satisfaction } \\
\quad \text { (Time 2) }\end{array}$ & $0.71 * *$ & 1 & $0.65 * *$ & $0.90 * *$ \\
\hline $\begin{array}{l}\text { Life satisfaction } \\
\quad \text { (Time } 3 \text { ) }\end{array}$ & $0.65 * *$ & $0.65 * *$ & 1 & $0.85 * *$ \\
\hline $\begin{array}{l}\text { Mean life } \\
\text { satisfaction }\end{array}$ & $0.90 * *$ & $0.90 * *$ & $0.85 * *$ & 1 \\
\hline $\begin{array}{l}\text { Self-esteem } \\
\quad \text { (Time 1) }\end{array}$ & $0.51 * *$ & $0.44 * *$ & $0.50 * *$ & $0.55 * *$ \\
\hline $\begin{array}{l}\text { Self-esteem } \\
\text { (Time 2) }\end{array}$ & $0.53 * *$ & $0.60 * *$ & $0.45 * *$ & $0.60 * *$ \\
\hline $\begin{array}{l}\text { Self-esteem } \\
\quad \text { (Time 3) }\end{array}$ & $0.44 * *$ & $0.40 * *$ & $0.51 * *$ & $0.51 * *$ \\
\hline $\begin{array}{l}\text { Mean } \\
\text { self-esteem }\end{array}$ & $0.53 * *$ & $0.51 * *$ & $0.52 * *$ & $0.59 * *$ \\
\hline $\begin{array}{l}\text { Reward for } \\
\text { application }\end{array}$ & -0.07 & -0.89 & -0.10 & -0.09 \\
\hline Social complexity & -0.17 & -0.15 & $-0.29 *$ & $-0.23 *$ \\
\hline Fate control & -0.03 & 0.03 & 0.04 & 0.01 \\
\hline Spirituality & $0.24^{*}$ & 0.17 & 0.08 & 0.18 \\
\hline Social cynicism & $-0.36 * *$ & $-0.33 * *$ & $-0.34 * *$ & $-0.39 * *$ \\
\hline
\end{tabular}

dimension from the correlation results. We did a simple regression analysis entering the belief dimension in predicting self-esteem as the potential mediator. Results show that the belief dimension of social cynicism was successful in predicting the mediator, $R^{2}=0.15, p<0.05$, standardized $B=-0.46$.

For the last required step to establish mediation, we entered the dimension of social cynicism into the second block of a hierarchical regression equation after entering self-esteem in the first block. When entered in the second block, social cynicism was no longer significant in predicting life satisfaction. This outcome showed that social cynicism was completely mediated by 
TABLE II

Correlations between self-esteem and social beliefs across time point

\begin{tabular}{lcccc}
\hline & $\begin{array}{l}\text { Self-esteem } \\
\text { (Time 1) }\end{array}$ & $\begin{array}{l}\text { Self-esteem } \\
\text { (Time 2) }\end{array}$ & $\begin{array}{l}\text { Self-esteem } \\
\text { (Time 3) }\end{array}$ & Mean self-esteem \\
\hline Self-esteem (Time 1) & 1 & $0.85^{* *}$ & $0.83^{* *}$ & $0.95^{* *}$ \\
Self-esteem (Time 2) & $0.85^{* *}$ & 1 & $0.80^{* *}$ & $0.94^{* *}$ \\
Self-esteem (Time 3) & $0.83^{* *}$ & $0.80^{* *}$ & 1 & $0.93^{* *}$ \\
Mean self-esteem & $0.95^{* *}$ & $0.94^{* *}$ & $0.93^{* *}$ & 1 \\
Reward for application & -0.16 & -0.15 & -0.22 & -0.20 \\
Social complexity & 0.04 & 0.08 & -0.01 & 0.03 \\
Fate control & -0.12 & -0.15 & -0.18 & -0.17 \\
Spirituality & 0.04 & 0.11 & -0.08 & 0.01 \\
Social cynicism & $-0.31^{* *}$ & $-0.40^{* *}$ & $-0.42^{* *}$ & $-0.39 * *$ \\
\hline
\end{tabular}

$* p<0.05 ; * * p<0.01$.

self-esteem in predicting life satisfaction $\left(R^{2}\right.$ change $=0.03$, $p=0.07)$.

A further analysis with the Sobel test confirmed the mediation model, showing that mean self-esteem can mediate the influence of social cynicism on life satisfaction $(z=-3.21, p<0.01)$. Figure 1 presents a graphical presentation of the model.

Additive prediction of life satisfaction by social complexity. We also explored whether each belief dimension would add predictive power in explaining life satisfaction after controlling for

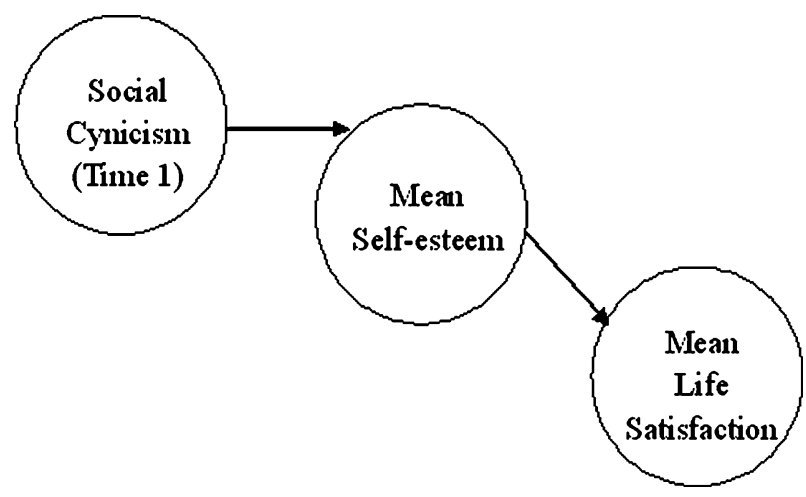

Figure 1. Mean self-esteem mediating between social cynicism and mean life satisfaction. 
self-esteem in separate, hierarchical regression analyses. As could have been predicted from the bivariate correlations, only social complexity showed a significant $R^{2}$ change, $\left(R^{2}\right.$ change $=0.06$, $p<0.01$ ). Social complexity, then, has a relationship with life satisfaction that is not mediated by self-esteem.

\section{Longitudinal analysis}

Path analysis. Even though the mediation tests seem to suggest the causal direction of influence from social cynicism to selfesteem to life satisfaction, one must be cautious about drawing this conclusion from correlational data. We tried to further develop evidence in support of the causal model and direction by exploiting the longitudinal nature of the dataset. We did path analyses using EQS (Bentler and $\mathrm{Wu}$, 1995) to explore the causal linkages of social cynicism belief, self-esteem and life satisfaction over time.

Figure 2 presents the standardized parameter estimation of a cross-time mediation model. Due to the small sample size, the chi-square is insignificant as expected, (chi-square $=3.06$, $p>0.05, \mathrm{df}=3$ ), but the model did show a satisfactory model fit with different fit indices. For example, the Comparative Fit Index, Bentler-Bonett Normed Fit Index, LISREL GFI Fit Index all yielded values above 0.9. These results are consistent with the argument that social cynical beliefs at the outset of the study lead to lower self-esteem level in the middle of the year, in turn leading to a lowered life satisfaction level after 1 year.

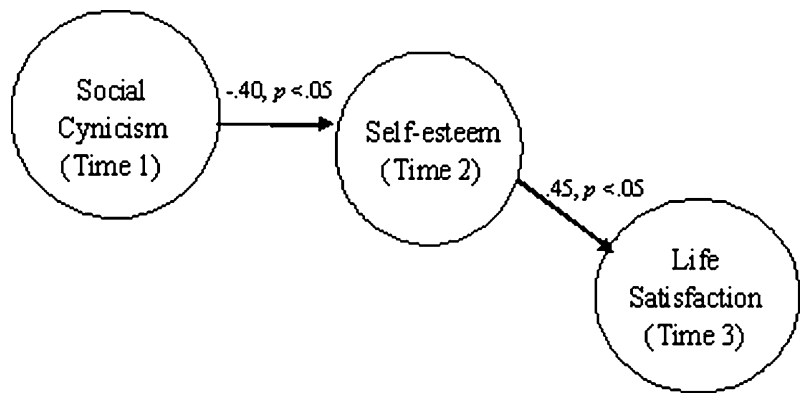

Figure 2. Parameter estimates of mediation path analysis model using EQS. 
Hierarchical regression. We also considered possible confounding effects on the correlations of variation within the three measures of self-esteem and of life satisfaction across time in our mediation model. To assess the possible impact of this variation, the standard deviations of self-esteem and life satisfaction across time were calculated. These scores were always entered into the first block of the following series of hierarchical regression analyses, so that the stability of self-esteem and life satisfaction over time were controlled. For the first regression analysis, time two self-esteem was entered as the dependent variable, with social cynicism entered in block two as the predictor. The results showed a significant impact of social cynicism in predicting time-two self-esteem $\left(R^{2}\right.$ change $\left.=0.11, p<0.01\right)$. A similar regression analysis was done for predicting time-three self-esteem, with the results again showing a significant impact of social cynicism in predicting time-three self-esteem $\left(R^{2}\right.$ change $=0.10, p<0.01)$. Therefore, social cynicism could lead to a prediction across time of self-esteem, given the control on the stability of self-esteem and life satisfaction.

Another two regression analyses were done in predicting life satisfaction at time two and time three. For predicting time-two life satisfaction, social cynicism again added significant prediction $\left(R^{2}\right.$ change $\left.=0.10, p<0.01\right)$. For predicting time-three life satisfaction, social cynicism also added significant prediction $\left(R^{2}\right.$ change $\left.=0.10, p<0.01\right)$. This series of hierarchical regression suggests further evidence of a causal role for social cynicism in predicting self-esteem and life satisfaction across time.

\section{DISCUSSION}

We regard social axioms as "the basic premises that people endorse and use to guide their behavior in daily living" (Bond et al., 2004b, p. 552), and used this theoretical position to relate these axioms to an individual's well-being. The hypothesized model shows some validity for the belief dimension of social cynicism. The longitudinal nature of the dataset and the statistical evidence from path analysis and hierarchical regression all 
suggested a possible causal influence of social cynicism on life satisfaction through the mediating agency of self system.

As suggested by this model, being sensitive to a client's socially cynical thoughts may be useful for counselors in doing well-being interventions. The present results suggest that a negative view about human nature and life in society will bring about less social engagement and more negative social feedback. This dynamic is in line with social cognition research showing that social cognitions will guide our interactions with others through a self-fulfilling process, resulting in more negative and fewer positive social outcomes (Babad et al., 1991; Jussim, 1986, 1993; Jussim et al., 1996). Such negative social feedback will be reflected in lower self-esteem which, in its turn, will result in lower satisfaction with one's life.

Our further ad hoc analyses from more variables in the dataset showed a negative relationship between social cynicism and the construct of relationship harmony, which was developed by Kwan et al. (1997), $r(78)=-0.26, p<0.05$.This further supports the notion that those who are socially cynical will have poorer social relationships with the five most significant others in their life, an outcome that may both arise from their social cynicism but also reinforce their negative beliefs about the rewards attainable from social life with others.

From the same ad hoc analyses, it is noteworthy that social cynicism is also negatively related to the respondent's grade point average (GPA) data obtained from two-thirds of these students throughout the year, $r(55)=-0.32, p<0.05$. Social cynicism appears to be associated with a set of poor life outcomes, perhaps arising from a cynicism-fueled withdrawal from trying; perhaps reflecting the person's various past failures in social and academic pursuits, or both. This lower social integration and acceptance will bring about a lower sense of worth because self-esteem is also built upon social feedback from various sources. Lesser satisfaction with one's life is the result.

Speculatively, one might consider social cynicism as another possible cultural variable in explaining the consistent national differences in life satisfaction across cultures. In cross-cultural research on well-being, Asians show lower levels 
of life satisfaction than Europeans and Caucasian North Americans (Diener et al., 2003). Comparing citizen scores on social cynicism across 41 nations, Leung and Bond (2004) found that students from Western European countries and North America showed the lowest levels; Hong Kong Chinese were among the most socially cynical. Our analysis of social cynicism in the current study has proposed and verified the linkage between social cynicism, self-esteem and life satisfaction. Perhaps then national differences in life satisfaction (Diener and Diener, 1995) could be explained by these varying levels of social cynicism and self-esteem.

\section{Insights About Self-esteem}

Our findings not only confirm the long recognized role of selfesteem in promoting well-being, but also point to its significance in relating other psychological factors, such as beliefs about the world in which the individual functions, to our evaluation of life. Through understanding these relations, we can learn more about the nature and sources of self-esteem, rarely researched issues in the voluminous literature on this fundamental construct (Leary et al., 1999). Our results also support the position that self-esteem has a strong social element, as seen by its relationship with social cynicism. It is probable that there exists another, closely related kind of self-esteem known as reflected self-esteem. According to Baumeister (1999), the self is socially constituted and develops from feedback generated by our social networks. We obtain our view about ourselves partly through the feedback from others, and this reflected self-esteem also helps us to better relate to others. There is no established measure of reflected self-esteem, so future research should include this construct in attempting to account for greater variance in well-being and life satisfaction.

\section{Additional Predictors of Life Satisfaction}

One surprising finding was that social complexity related negatively to life satisfaction, but did not do so through the mediating agency of self-esteem. Future research can examine how the belief that the world is complex and that people are changeable 
will affect well-being. How does a higher level of belief in social complexity reflect and frustrate the attainment of the personal and interpersonal successes that underpin life satisfaction? We know that higher social complexity characterizes those who adopt a problem-solving coping style and a compromising approach to conflict resolution (Bond et al., 2004a). These approaches to dealing with interdependencies would seem designed to elicit more positive, not more negative, life outcomes. Perhaps higher social complexity relates to another, as yet unknown mediator of life satisfaction, resulting in a lower level of this crucial outcome. One speculation is that people who hold this belief will have lower trust in others who, they believe, are ever-changing, and will feel dissatisfied with having to adapt and change themselves constantly to accommodate others.

\section{Future Directions}

The current paper attempted to propose a general path model to describe the influence of social beliefs in affecting well-being. We are, however, aware of the limitations in this exploratory study - its limited sample size, and its sampling of college students from a specific culture. The model provides a general framework, however, for future study on how social cognitions can affect well-being, and how different pathways may work differently across cultural groups. For example, the relationship between social beliefs and self-esteem may be more powerful among Asian cultures as compared to the European-American, given that Asians emphasize an interdependent self-construal more (Singelis and Brown, 1995). It has yet to be explored if social beliefs play different roles across culture in affecting wellbeing.

Future study can also explore whether social beliefs affect aspects of subjective well-being other than life satisfaction, as suggested from the sequential framework of studying subjective well-being proposed by $\mathrm{Chu}$ et al. (2005). For example, studies can examine whether social beliefs affect the strength of emotional reactions to a specific context or events. In addition, we did not measure the social experience and behaviors component 
of our hypothesized model. Further studies need to investigate how an individual's past experience influence the development of one's social beliefs, as well as how these beliefs about the world function to create different social experiences.

\section{Implications for Interventions}

As with studies identifying how distorted cognitions lead to emotional problems (e.g., depression), our study attempted to identify some conscious cognitions that will affect life satisfaction. Our findings suggest that if a therapist wanted to treat a person who is constantly complaining about his dissatisfaction with life, that therapist should be sensitive to the client's social beliefs, and speculate how these taken-for-granted beliefs about the world may impact on his or her social experience and selfesteem. In particular, our findings direct attention to socially cynical beliefs in any deliberate attempts to promote a good life, an agenda compatible with programs for character education, life coaching, or after-school youth development (e.g., Berkowitz, 2002; Kilburg, 1996; Roth and Brooks-Gunn, 2003). Our findings also suggest that the socially cynical thoughts should be brought to the client's attention as being a lose-lose strategy that will not bring benefits to the client. Cognitive change interventions in these programs could then focus on aligning goals with attainable reality in the client's current environment.

\section{REFERENCES}

Andrews, F.M. and S.B. Withey: 1976, Social Indicators of Well-being: America's Perception of Life Quality (Plenum Press, New York).

Babad, E., F. Bernieri and R. Rosenthal: 1991, 'Students as judges of teachers' verbal and nonverbal behaviour', American Educational Research Journal 28, pp. 211-234.

Barron, R.M. and D.A. Kenny: 1989, 'The moderator-mediator variable distinction in social psychological research: Conceptual, strategic, and statistical considerations', Journal of Personality and Social Psychology 51, pp. 1173-1182. 
Baumeister, R.F.: 1999, The nature and structure of the self: An overview, in R.F. Baumeister (ed.), The Self in Social Psychology (Edwards Brother, Ann Arbor, MI), pp. 1-20.

Bentler, P.M. and E.J.C. Wu: 1995, EQS for Windows Users Guide (Multivariate Software, Inc, Encino, CA).

Berkowitz, M.W.: 2002, The science of character education, in W. Damon (ed.), Bringing in a New Era in Character Education (Hoover Institution Press, Stanford, CA), pp. 43-63.

Bond, M.H., K. Leung, A. Au, K.K. Tong and Z. Chemonges-Nielson: 2004a, 'Combining social axioms with values in predicting social behaviours', European Journal of Personality 18, pp. 177-191.

Bond, M.H., K. Leung, A. Au, K-K. Tong, S.R. CarrasquelDe and F. Murakami : 2004b, 'Culture-level dimensions of social axioms and their correlates across 41 cultures', Journal of Cross-Cultural Psychology 35(5), pp. 548-570.

Chu, K-P, E. Diener, M. Tamir, C. Scollon and M. Diener: 2005, 'Integrating the diverse definitions of happiness: A time sequential framework of subjective well-being', Journal of Happiness Studies 6, pp. 261-300.

Darley, J.M. and R.H. Fazio: 1980, 'Expectancy confirmation processes arising in the social interaction sequence', American Psychologist 35, pp. 867-881.

Diener, E.: 1984, 'Subjective well-being', Psychological Bulletin 95, pp. 542-575.

Diener, E. and M. Diener: 1995, 'Cross-cultural correlates of life satisfaction and self-esteem', Journal of Personality and Social Psychology 68(4), pp. 653-663.

Diener, E., R.A. Emmons, R.J. Larson and S. Griffin: 1985, 'The satisfaction with life scale', Journal of Personality Assessment 49, pp. 71-75.

Diener, E. and R.J. Larsen: 1993, The experience of emotional well-being, in M. Lewis and J.M. Haviland (eds.), Handbook of Emotions (Guilford Press, New York), pp. 405-415.

Diener, E., S. Oishi and R.E. Lucas: 2003, 'Personality, culture, and subjective well-being: Emotional and cognitive evaluations of life', The Annual Review of Psychology 54, pp. 403-425.

Diener, E., E.M. Suh, R.E. Lucas and H.L. Smith: 1999, 'Subjective well-being: Three decades of progress', Psychological Bulletin 125(2), pp. 276-302.

Hui, N.H.H.: 2004, 'Personal goals and goal pursuit processes among Hong Kong university students: A longitudinal study'. Thesis, Department of Psychology, the Chinese University of Hong Kong, Hong Kong.

Jussim, L.: 1986, 'Self-fulfilling prophecies: A theoretical and integrative review', Psychological Review 93, pp. 429-445.

Jussim, L.: 1993, 'Accuracy in interpersonal expectations: A reflection-construction analysis of current and classic research', Journal of Personality 61, pp. 637-668.

Jussim, L., J. Eccles and S. Madon: 1996, Social perception, social stereotypes, and teacher expectations: Accuracy and the quest for the powerful 
self-fulfilling prophecy, in M.P. Zanna (ed.), Advances in Experimental Social Psychology (Academic Press, New York), pp. 1-65.

Kilburg, R.R.: 1996, 'Toward a conceptual understanding and definition of executive coaching', Consulting Psychology Journal: Practice and Research 48, pp. 134-144.

Kitayama, S. and H.R. Markus: 1995, Culture and self: Implications for internationalizing psychology, in N.R. Goldberger and J.B. Veroff (eds.), The Culture and Psychology Reader (New York University Press, New York), pp. 366-383.

Kwan, V.S.Y., M.H. Bond and T.M. Singelis: 1997, 'Pancultural explanations for life satisfaction: Adding relationship harmony to self-esteem', Journal of Personality and Social Psychology 73, pp. 1038-1051.

Lachman, M.E. and S.L. Weaver: 1998, 'The sense of control as a moderator of social class differences in health and well-being', Journal of Personality and Social Psychology 74, pp. 763-773.

Leary, M.R.: 1998, The social and psychological importance of self-esteem, in R.M. Kowalski and M.R. Leary (eds.), The Social Psychology of Emotional and Behavioral Problems (American Psychological Association, Washington, DC), pp. 197-222.

Leary, M.R., E.S. Tambor, S.K. Terdal and D.L. Downs: 1999, Self-esteem as an interpersonal monitor: The sociometer hypothesis, in R.F. Baumeister (ed.), The Self in Social Psychology (Edwards Brother, Ann Arbor, MI), pp. 87-104.

Leung, K. and M.H. Bond: 2004, Social axioms: A model for social beliefs in multicultural perspective, in M.P. Zanna (ed.), Advances in Experimental Social Psychology vol. 36 (Elsevier Academic Press, San Diego, CA), pp. 119-197.

Leung, K., M.H. Bond, S.R. CarrasquelDe, C. Muñoz, M. Hernández, F. Murakami, S. Yamaguchi, G. Bierbrauer and T. Singelis: 2002, 'Social axioms: The search for universal dimensions of general beliefs about how the world functions', Journal of Cross-Cultural Psychology 33, pp. 286-302.

Marsh, H.W., C-K. Kong and K-T. Hau: 2000, 'Longitudinal multilevel models of the big-fish-little-pond effect on academic self-concept: Counterbalancing contrast and reflected-glory effects in Hong Kong schools', Journal of Personality and Social Psychology 78, pp. 337-349.

Rosenberg, M.: 1965, Society and the Adolescent Self-image (Princeton University Press, Princeton, NJ).

Roth, J.L. and J. Brooks-Gunn: 2003, 'Youth development programs: Risk, prevention, and policy', Journal of Adolescent Health 32, pp. 170-182.

Scheier, M.F. and C.S. Carver: 1985, 'Optimism, coping, and health: Assessment and implications of generalized outcome expectancies', Health Psychology 4, pp. 219-247.

Shepperd, J.A. and K.M. Taylor: 1999, 'Ascribing advantages to social comparison targets', Basic and Applied Social Psychology 21, pp. 103-117. 
Singelis, T.M. and W.J. Brown: 1995, 'Culture, self, and collectivist communication: Linking culture to individual behavior', Human Communication Research 21, pp. 354-389.

Steele, C.M.: 1997, 'A threat in the air: How stereotypes shape intellectual identity and performance', American Psychologist 52, pp. 613-629.

Taylor, S.E. and D.A. Armor: 1996, 'Positive illusions and coping with adversity', Journal of Personality 64, pp. 873-898.

Todd, J. and C.B. Arthur: 1994, Foundations of Clinical and Counseling Psychology (2nd ed)(Harper Collins College, New York).

Address for correspondence:

MICHAEL HARRIS BOND

Department of Psychology

The Chinese University of Hong Kong,

Shatin, New Territories,

Hong Kong.

E-mail:mhb@cuhk.edu.hk 